\title{
CRÍTICA AO ZONEAMENTO DE USO E OCUPAÇÃO DO SOLO COMO UM INSTRUMENTO DE GESTÃO NA SUB-BACIA HIDROGRÁFICA DO RIBEIRÃO DA CACHOEIRINHA - BELO HORIZONTE/MINAS GERAIS ${ }^{1}$
}

\author{
Lucas Luiz Senhorine Pena $^{(a)}$, Felipe Fernandes Ladislau ${ }^{(b)}$ \\ (a) Departamento de Geografia, Universidade Federal de Minas Gerais, lucassenhorine91@ gmail.com \\ (b) Departamento de Geografia, Universidade Federal de Minas Gerais, felipe.fernandesladislau @live.com
}

\section{EIXO: BACIAS HIDROGRÁFICAS E RECURSOS HÍDRICOS: ANÁLISE, PLANEJAMENTO E GESTÃO}

\begin{abstract}
Resumo
Este artigo tem como proposta analisar os aspectos físicos e sócio espaciais recorrentes na Subbacia hidrográfica do Ribeirão da Cachoeirinha, de modo a investigar os processos-chave que acarretam na maior ocorrência de inundações, bem como na alteração do comportamento hídrico da Sub-bacia. Através de uma leitura analítica e interpretativa de documentos, produções acadêmicas e relatórios de gestão e planejamento, bem como a identificação da dinâmica da ocorrência de inundações e da ocupação urbana no local, tende-se a refletir sobre as formas e instrumentos de gestão no local, além de propor soluções aos problemas enfrentados pelo processo de ocupação da sub-bacia. Parte-se do pressuposto que o adensamento urbano associado a problemas teórico-conceituais nos planos de gestão e zoneamento de Belo Horizonte sejam causa considerável nos impactos, tanto ambientais como urbanos, na sub-bacia, bem como as alterações em seu sistema ambiental.
\end{abstract}

Palavras chave: Sub-bacia hidrográfica, inundação, zoneamento, Cachoeirinha.

\section{INTRODUÇÃO}

As bacias hidrográficas localizadas em áreas urbanas estão sujeitas a processos antrópicos que modificam a sua dinâmica em relação àquelas localizadas em áreas pouco antropizadas. Em áreas urbanas, a implementação de infraestruturas e equipamentos urbanos, - oriundos do intenso processo de ocupação do solo, muitas vezes desordenado -, são fatores cujas consequências trazem consigo desafios no que tange a gestão, tanto dos recursos e processos naturais vigentes em bacias hidrográficas, como do uso e ocupação do solo. Os desafios aos gestores de bacias localizadas no perímetro urbano normalmente perpassam pela ocorrência de inundações. A definição de inundação adotada para o presente trabalho refere-se a tal processo como o "[...] transbordamento das águas de um curso d’água, atingindo a planície de inundação ou área da várzea” (TOMINAGA et al. 2009. p. 42). Diferentemente das inundações as enchentes são definidas pela elevação do nível d'água no canal de drenagem devido ao aumento da vazão, atingindo a cota máxima do canal, porém, sem extravasar.

\footnotetext{
${ }^{1}$ Este artigo é resultado da revisão do projeto de Monografia realizado pelo graduando Lucas Pena, para conclusão de seu período de graduação em Geografia. Para a realização deste artigo, contou-se com a participação do também graduando em Geografia Felipe Ladislau, auxiliando na elaboração estrutural do texto, bem como na elaboração e/ou seleção dos dados secundários.
} 
(TOMINAGA et al, 2009).

Tucci (2002, p.8) associa as inundações urbanas à impermeabilização e ocupação do solo, à construção de redes de condutos pluviais e ao aumento da produção de sedimentos durante períodos de precipitação devido à exposição da superfície descoberta, gerando assim o assoreamento dos canais fluviais. Já Cajazeiro (2012, p.26) associa o aumento da vazão dos cursos d'água ao despejo de esgoto sobre estes cursos d'água. Logo, notam-se como as obras de infraestrutura e as demandas de serviços básicos como esgotamentos sanitários interferem sobre as dinâmicas hídricas de um canal fluvial. Tal contexto urbano tende a gerar um aumento em até sete vezes sobre o valor da vazão máxima de um curso d'água, segundo Leopold (1968) (apud. TUCCI. 1997, p.5).

Como consequência desse processo, ocorreu impacto considerável nos recursos hídricos das redes hidrográficas presentes na bacia, na medida em que se intensificou o escoamento superficial - com a impermeabilização - em cursos e drenagens canalizadas pelo processo urbano, aumentando as probabilidades de inundação (FELIPPE et. al., 2011) - um desafio em relação às formas de gestão das redes de drenagem e escoamento municipais. Isso se associa ao aparato realizado pelo município no que tange aos investimentos de infraestrutura, muitos deles carentes, tanto de planejamento existente e/ou aplicado, como de recursos financeiros provenientes para a sua realização, colaborando assim para a intensificação de tais inundações, bem como acidentes consequentes.

\section{OBJETIVO}

Em vista disso, este trabalho objetiva a identificação e análise das variáveis naturais e antrópicas verificadas na sub-bacia hidrográfica do Ribeirão da Cachoeirinha, localizada, sobretudo na porção nordeste do município de Belo Horizonte, como verificado no mapa da figura 1. Dentre as variáveis a serem investigadas têm-se os aspectos urbanísticos; a declividade na qual a sub-bacia hidrográfica está inserida; o Zoneamento de Áreas de Especial Interesse Social, Áreas de Diretrizes Especiais e Hierarquia Viária do Município, adotado pela Prefeitura de Belo Horizonte; e o uso e ocupação do solo a partir de uma perspectiva evolutiva temporal. Após apurar as variáveis, é realizada uma verificação dos desdobramentos ${ }^{2}$ sobre as inundações do Ribeirão da Cachoeirinha, com o propósito de analisar a efetividade das ações propostas pelos gestores municipais.

\footnotetext{
${ }^{2}$ Os desdobramentos neste caso se referem sobretudo às ações e políticas de gestão adotadas que objetivam reduzir a frequência inundações para o caso do Ribeirão da Cachoeirinha.
} 


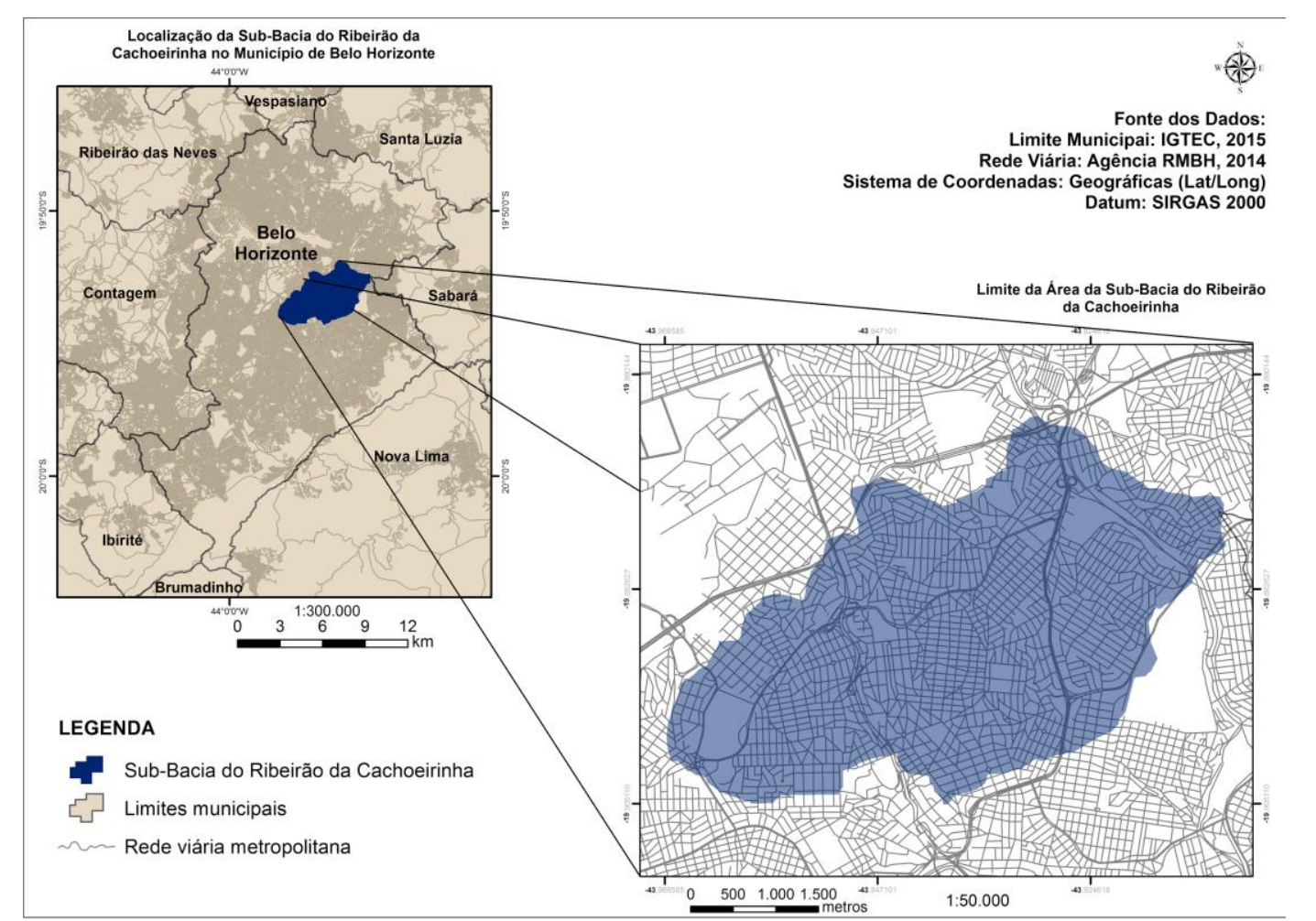

Figura 1. Localização da Sub-Bacia Hidrográfica do Ribeirão da Cachoeirinha no município de Belo Horizonte. Fonte: Elaborado pelos autores

\section{PROCEDIMENTOS METODOLÓGICOS}

O desenvolvimento do presente trabalho esteve fundamentado em métodos capazes de subsidiar a análise das inundações na sub-bacia hidrográfica do Ribeirão da Cachoeirinha. Para tal, foram considerados, sobretudo, aspectos presentes no contexto urbano que interferem no comportamento superficial do escoamento da água pluvial.

A primeira fase da pesquisa compreendeu na definição da área de estudo. As justificativas que incidiram sobre a escolha da sub-bacia do Ribeirão da Cachoeirinha referem-se às taxas de declividade observadas para a sub-bacia, que em sua maioria apresenta um relevo plano a ondulado ${ }^{3}$, excetuandose algumas porções da sub-bacia caracterizadas como relevo forte-ondulado. As taxas de declividade foram definidas como fator preponderante à adoção da área de estudo, pois a ocorrência de inundações está normalmente associada às taxas de declividade mais elevadas.

A revisão bibliográfica consistiu na leitura de materiais referentes aos conceitos de inundação, declividade, planejamento e zoneamento, como forma de aporte a elaboração do tema, além das leis complementares referentes ao uso e ocupação do solo na sub-bacia do Cachoeirinha. A primeira etapa consistiu em um levantamento de dados secundários referente ao número de inundações do Ribeirão

\footnotetext{
${ }^{3}$ Segundo classificação adotada pela EMBRAPA (1979).
} 
da Cachoeirinha. Posteriormente foram selecionadas bases cartográficas, pertinentes ao zoneamento ${ }^{4}$ do município de Belo Horizonte. Esse, a propósito, recebeu um recorte espacial referente a área de estudo trabalhada, de modo a analisar a sua proposta de adensamento, parcelamento e urbanização dentro do recorte de estudo, bem como a permitir a identificação de áreas destinadas a proposta do projeto e as não destinadas, sob proteção. Além disso, foram utilizadas fotos aéreas da sub-bacia hidrográfica do Ribeirão da Cachoeirinha, produzidas pelo DEER-MG (Departamento de Edificações e Estradas e Rodagem de Minas Gerais) ${ }^{5}$ datam de 1967 e 1983 e, por meio do Google Earth,foi obtida a imagem de satélite para o ano de 2016. Uma interpretação de tais fotos aéreas e imagem de satélite fora realizada e, logo após, por meio do softwareArcgis foi produzida uma vetorização, que permitiu a delimitação de áreas não impermeabilizadas. A identificação e espacialização de tais porções da sub-bacia possibilitou a verificação da expansão da mancha urbana. A delimitação da subbacia do Ribeirão da Cachoeirinha foi feita através da carta SE-23-C-Z obtida através do Projeto Brasil em Relevo, de responsabilidade da EMBRAPA - Empresa Brasileira de Pesquisa Agropecuária - (MIRANDA, 2005) equivalente a imagem SRTM do Estado de Minas Gerais.

\section{RESULTADOS E DISCUSSÕES}

\section{Evolução histórico-temporal das transformações do uso e ocupação do solo}

As inundações formadas em núcleos urbanos, conforme Goerl e Kobiyama (2005) podem ser classificadas como inundações bruscas, caracterizadas como uma inundação formada em um tempo próximo à ocorrência de precipitações de intenso volume.

No decorrer dos anos o adensamento populacional em Belo Horizonte ${ }^{6}$ foi intensificado, especialmente a partir da década de 1960, com a consolidação industrial da cidade, o que gerou a expansão da mancha urbana a regiões mais ao norte, como as atuais regionais Nordeste (foco do estudo), Pampulha e Venda Nova. Em razão disso, considerou-se adequado o mapeamento ${ }^{4}$ de áreas não impermeabilizadas ${ }^{7}$ para os anos de 1967, 1983 e 2016. É evidente que o comportamento hidrológico difere em áreas superficiais cobertas por vegetação e em áreas de solo exposto, a primeira é caracterizada por uma infiltração da água de modo que não produza um volume de sedimentos semelhante ao verificado em áreas de solo exposto. Diante disso, o estabelecimento das áreas não

\footnotetext{
${ }^{4}$ O referido zoneamento corresponde ao "Zoneamento, Áreas de Especial Interesse Social, Áreas de Diretrizes Especiais e Hierarquia Viária do Município de Belo Horizonte (Lei no 7166/96 e alterações 2012)”, elaborado pela Prefeitura de Belo Horizonte, através da Secretaria Municipal de Desenvolvimento e da Secretaria Municipal Adjunta de Planejamento Urbano. ${ }^{5}$ Antigo Departamento de Estradas de Rodagem (DER-MG), remodelado em 2016.

${ }^{6}$ De acordo com Felippe et. al. (2011), o adensamento populacional, junto do processo de urbanização de Belo Horizonte, teve um crescimento vertiginoso entre as décadas de 1970 e 1980, decorrentes da expansão metropolitana através dos grandes eixos metropolitanos.

${ }^{7}$ As denominadas áreas não impermeabilizadas são as áreas de solo exposto e de cobertura vegetal, independente do fato de tais áreas estarem parceladas.
} 


$\begin{aligned} & \text { XVII Simpósio Brasileiro } \\ & \text { de Geografia Fisica Aplicada }\end{aligned}$
$\begin{aligned} & \text { I Congresso Nacional } \\ & \text { de Geografia Física }\end{aligned}$

impermeabilizadas seguiu uma concepção pautada no modo como a água se comporta sobre as superfícies, isto é, se há o predomínio de infiltração ou do escoamento superficial.

O ano de 1967 é de grande relevância para a análise do aumento da ocorrência de inundações, já que em 1966 foram iniciadas as obras de canalização do Ribeirão da Cachoeirinha. A adoção de medidas estruturais como canalização de córregos usualmente estão relacionadas, de acordo com Champs, Perez \&Fróez (2001) às seguintes situações:

[...] (a) $\mathrm{O}$ curso d'água transformou-se em esgoto a céu aberto; (b) a comunidade deseja a canalização; (c) a canalização é necessária para viabilizar a implantação de uma via; (d) a canalização possibilita a implantação dos interceptores de esgotos; (e) a canalização facilita a manutenção do córrego, e (f) o córrego deve ser canalizado para aumentar a velocidade de escoamento e reduzir os níveis de pico das cheias e, consequentemente, reduzir as ocorrências de inundações (CHAMPS, PEREZ \& FRÓEZ, 2001, p. 2).

O mapa da figura 2 expõe as áreas não impermeabilizadas entre 1967 e 2016, para o ano de 1967 a sub-bacia do Cachoeirinha registrou como áreas não impermeabilizadas um total de $56.886,3 \mathrm{~m}^{2}$. De acordo com o referido mapa uma significativa parte das áreas não impermeabilizadas representadas em verde escuro equivale às áreas de cobertura vegetal e de solo exposto parcelado, este último justificado pela realização de obras no interior e próximo ao limite da sub-bacia do Cachoeirinha.

De acordo com a análise das áreas não impermeabilizadas em 1983 houve uma queda sobre o tamanho das áreas não impermeabilizadas. Tal redução representou uma perda aproximada de $10.000 \mathrm{~m}^{2}$, contribuindo assim para o aumento da vazão natural do Ribeirão da Cachoeirinha devido ao aumento da taxa de escoamento superficial da água proveniente das precipitações. Esta redução esteve condicionada, sobretudo, pela impermeabilização das já mencionadas áreas de solo exposto parceladas evidenciadas em 1967, além da impermeabilização de áreas anteriormente caracterizadas como cobertura vegetal. Uma das áreas mantidas como áreas não impermeabilizadas corresponde ao Museu de História Natural da Universidade Federal de Minas Gerais, caracterizada por uma cobertura vegetal de porte arbóreo.

Já o ano de 2016 indicou uma nova redução das áreas não impermeabilizadas em uma proporção semelhante a foto aérea do ano de $1983\left(10.000 \mathrm{~m}^{2}\right)$. Logo, foi identificado um total de $36.334,41 \mathrm{~m}^{2}$. Devido a qualidade da imagem de satélite fornecida pelo Google Earth cogitou-se a possibilidade do mapeamento de 2016 apresentar valores próximos às áreas não impermeabilizadas em 1983. Entretanto mesmo que o mapeamento permitisse a vetorização em uma escala de análise maior o ano de 2016 é caracterizado por uma intensa modificação antrópica. 


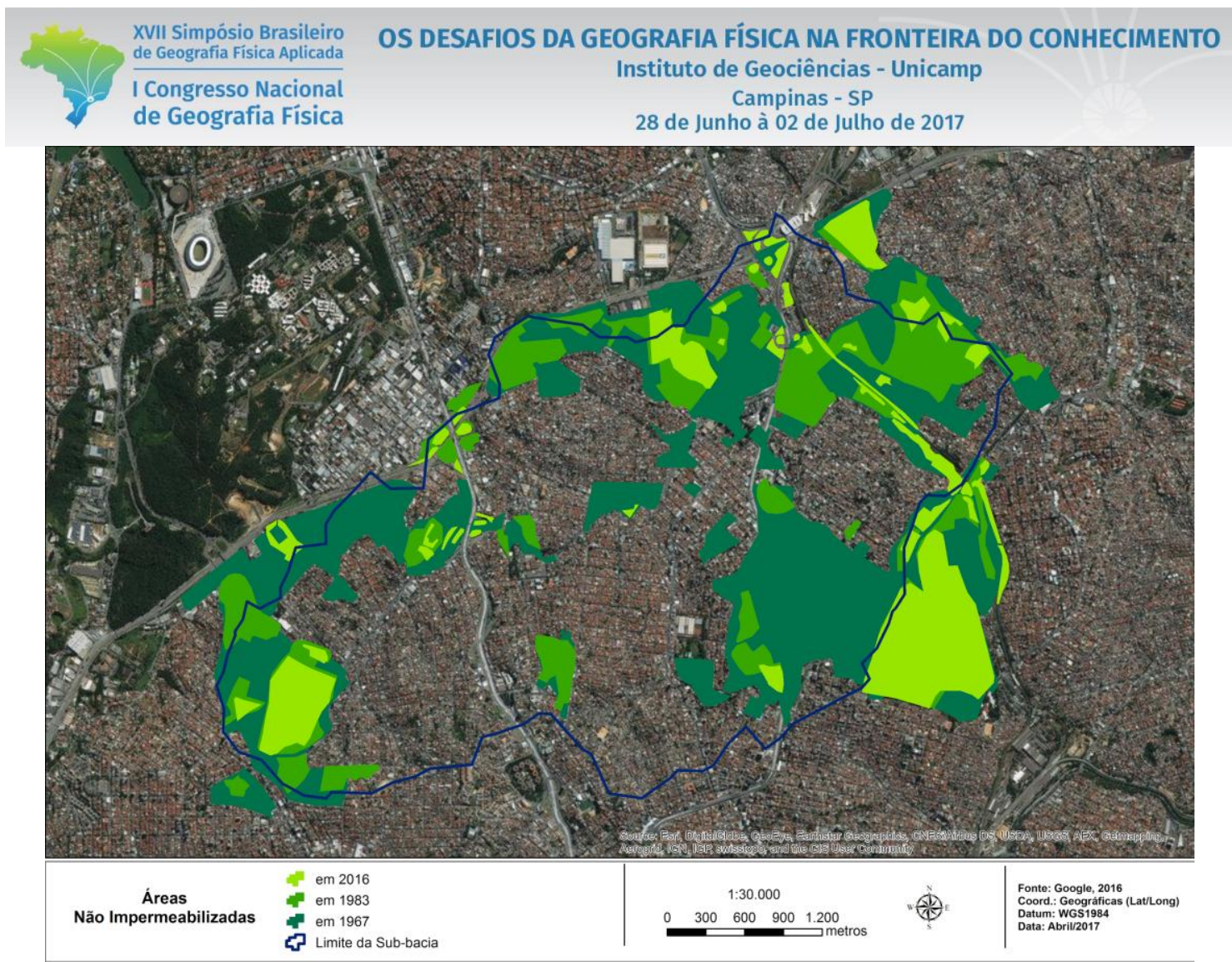

Figura 2. Mapeamento de areias não impermeabilizadas na Sub-bacia do Ribeirão da Cachoeirinha durante os anos de 1967, 1983 e 2016. Fonte: Elaborado pelos autores.

Após o mapeamento para 2016, verificou-se que as principais áreas não impermeabilizadas equivalem ao Museu de História Natural da Universidade Federal de Minas Gerais, ao Parque Ecológico Renato Azeredo, ao Parque Orlando de Carvalho da Silveira e ao Cemitério da Paz. Tais áreas são caracterizadas pela presença de cobertura vegetal o que confere a estas áreas um caráter preservacionista.

\section{Declividade e Malha Viária: Suas Atuações sobre os processos de Inundações}

Deacordo com Castro (2003, p.50) as enxurradas ao escoarem por um relevo acidentado alcançam o canal fluvial proporcionando o aumento da vazão natural do curso d'água, favorecendo assim a formação de inundações. Entretanto, conforme o mapa da figura 3 as taxas de declividade da sub-bacia do Cachoeirinha são relativamente baixas. As maiores taxas de declividade localizam-se em áreas de nascente, isto é, a montante dos locais de ocorrência de inundações, já a rede hidrográfica está assentada sobre declividades que variam entre 0 e $10 \%$. No que tange a malha viária próxima ao trecho do Ribeirão (trecho canalizado e aberto) as taxas de declividade verificadas nessa porção equivale, sobretudo entre 0 e 20\%. Segundo valores adotados pela EMBRAPA (1979) o relevo seria caracterizado como suave-ondulado a ondulado. Entretanto, as transformações antrópicas modificaram a configuração do relevo de tal modo que alguns aspectos naturais relevantes em uma análise sobre inundações, como a declividade, tendem a ter menor representatividade para a formação de inundações. 


$\begin{aligned} & \text { XVII Simpósio Brasileiro } \\ & \text { de Geografia Fisica Aplicada }\end{aligned}$
$\begin{aligned} & \text { I Congresso Nacional } \\ & \text { de Geografia Física }\end{aligned}$$\quad \begin{gathered}\text { CS DESAFIOS DA GEOGRAFIA FISICA NA FRONTEIRA DO CONHECIMENTO } \\ \text { Instituto de Geociências - Unicamp } \\ \text { Campinas - SP }\end{gathered}$

Logo, cogitou-se a possibilidade da malha viária representar uma das principais variáveis a contribuir para a formação das inundações, uma vez que sua geometria quadriculada favorece o escoamento das águas pluviais em direção ao Ribeirão da Cachoeirinha, além da geometria quadriculada não exercer qualquer anteparo ao escoamento da água, o sentido perpendicular da malha viária em direção ao Ribeirão da Cachoeirinha (trecho canalizado e aberto) possibilita o aumento da vazão média do canal fluvial. O sentido perpendicular da malha viária pode ser justificado pelo Ribeirão localizar-se em uma via de acesso principal ${ }^{8}$, portanto as demais vias convergem nesse sentido para garantir o acesso a via principal.

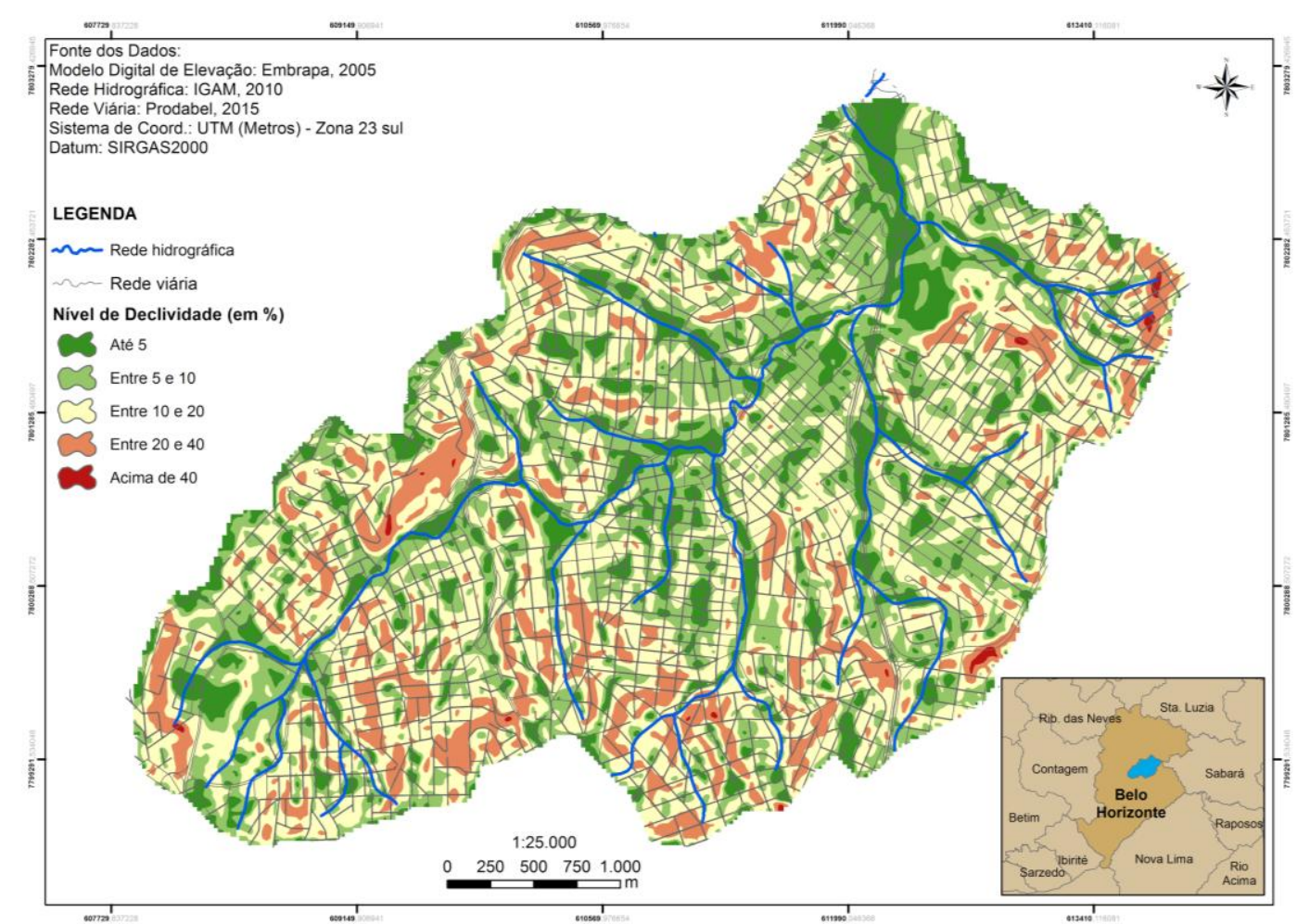

Figura 3. Mapa do percentual de declividade do terreno da Sub-bacia do Ribeirão da Cachoeirinha. Fonte: Elaborado pelos autores com dados do Projeto Brasil em Relevo (MIRANDA, 2005).

\section{Implicações do Zoneamento de Uso e Ocupação do Solo}

A análise sobre os eventos de inundação perpassa pela forma de ocupação e uso do solo na bacia hidrográfica. A fim de estabelecer um estudo acerca do zoneamento ambiental da sub-bacia hidrográfica em questão foi analisada a lei no 9.959, de 20 de Julho de 2010, que:

\footnotetext{
${ }^{8}$ Avenida Bernardo Vasconcelos.
}

[...] altera as leis $\mathrm{n}^{\circ} 7.165 / 96$ - e institui o Plano Diretor do Município de Belo Horizonte - $\mathrm{n}^{\circ} 7.166 / 96$ - que estabelece normas e condições para parcelamento, ocupação e uso do solo urbano no Município - estabelece normas e condições para a urbanização e a 


\section{OS DESAFIOS DA GEOGRAFIA FÍSICA NA FRONTEIRA DO CONHECIMENTO \\ Instituto de Geociências - Unicamp Campinas - SP \\ 28 de Junho à 02 de Julho de 2017}

regularização fundiária das Zonas de Especial Interesse Social, dispõe sobre parcelamento, ocupação e uso do solo nas Áreas de Especial Interesse Social, e dá outras providências

No caso da sub-bacia hidrográfica do Ribeirão da Cachoeirinha, esta compreende as seguintes categorias: ZA (Zona Adensada), ZAP (Zona de Adensamento Preferencial), ZAR-2 (Zona de Adensamento Restrito-2), ZE (Zona de Grandes Equipamentos). ZEIS-1 (Zona de Especial Interesse Social-1), ZP-1 (Zona de Proteção-1), ZPAM (Zona de Preservação Ambiental). O mapa da figura 4 representa a espacialização das categorias citadas acima.

A categoria Zona Adensada representada pela cor cinza constitui uma área onde a ocupação necessita ser contida, em razão do já elevado adensamento demográfico. Qualquer incentivo à ocupação poderia sobrecarregar a infraestrutura local. Já as zonas de categoria preferencial (ZAP), que englobam a maior parte da área da sub-bacia, são caracterizadas pela favorabilidade de ocupação, tanto de parte residencial como de infraestruturas e equipamentos. É interessante apontar que, por englobar grande parte da sub-bacia a ZAP está sujeita a maioria dos eventos de inundação que podem ser acarretados de uma ocupação e/ou uso do solo, permitidos por essa categoria de zoneamento. Outro ponto importante na análise das variáveis do zoneamento diz respeito ao Coeficiente de Aproveitamento ${ }^{9}$ (CA) das zonas, que apresentam valores muito próximos, mesmo em categorias distintas no que tange ao tipo de uso/ocupação, como, por exemplo, entre a Zona de Adensamento Preferencial (ZAP) e a Zona de Adensamento (ZA), respectivamente 1,7 e 1,5 (Lei 7.165/96, de 1996). Além dos valores de coeficiente de aproveitamento, há também os valores destinados às taxas de permeabilização ${ }^{10}$, no caso das categorias dispostas na sub-bacia do Cachoeirinha os valores de permeabilização correspondem a $95 \%$ para a ZPAM e $70 \%$ para a ZP-1, as demais categorias ${ }^{11}$ apresentam valores de $20 \%$ para a taxa de permeabilização. No entanto, de acordo com a seção II subseção V da Taxa de Permeabilidade do Capítulo IV da Lei no 7.166/96

[...] $\S 2^{\circ}$ - As edificações, exceto as localizadas na ZPAM e ZP podem impermeabilizar até $100 \%$ (cem por cento) da área do terreno, desde que:

I - nelas haja área descoberta - equivalente à área de permeabilidade mínima - dotada de vegetação que contribua para o equilíbrio climático;

[...] II - seja construída caixa de captação e drenagem que retarde o lançamento das

\footnotetext{
${ }^{9}$ É a relação entre a área total construída (soma da área de todos os pavimentos) em um terreno e a área desse mesmo terreno. Mede o volume de construção que um terreno comporta (VILLAÇA, 1998, p.5) .

${ }^{10}$ Seção IIsubseção V da Taxa de Permeabilidade do Capítulo IV da Lei no 7.166/96. Art. 50 - Considera-se Taxa de Permeabilidade a área descoberta e permeável do terreno em relação à sua área total, dotada de vegetação que contribua para o equilíbrio climático e propicie alívio para o sistema público de drenagem urbana.

${ }^{11}$ Exceto as ZEIS-1 e ZE ambas estão sujeitas a legislação específica
} 


$\begin{gathered}\text { XVII Simpósio Brasileiro } \\ \text { de Geografia Fisica Aplicada }\end{gathered}$
$\begin{aligned} & \text { I Congresso Nacional } \\ & \text { de Geografia Física }\end{aligned}$

águas pluviais provenientes da área de que trata o inciso I deste parágrafo ${ }^{12}$.

Logo, a sub-bacia do Cachoeirinha está sujeita a ser impermeabilizada quase que em sua totalidade, excetuando-se as áreas de ZPAM e ZP-1. Contudo, tais áreas destinadas às práticas conservacionistas possuem uma representatividade muito pequena se comparadas à dimensão total da área da sub-bacia.

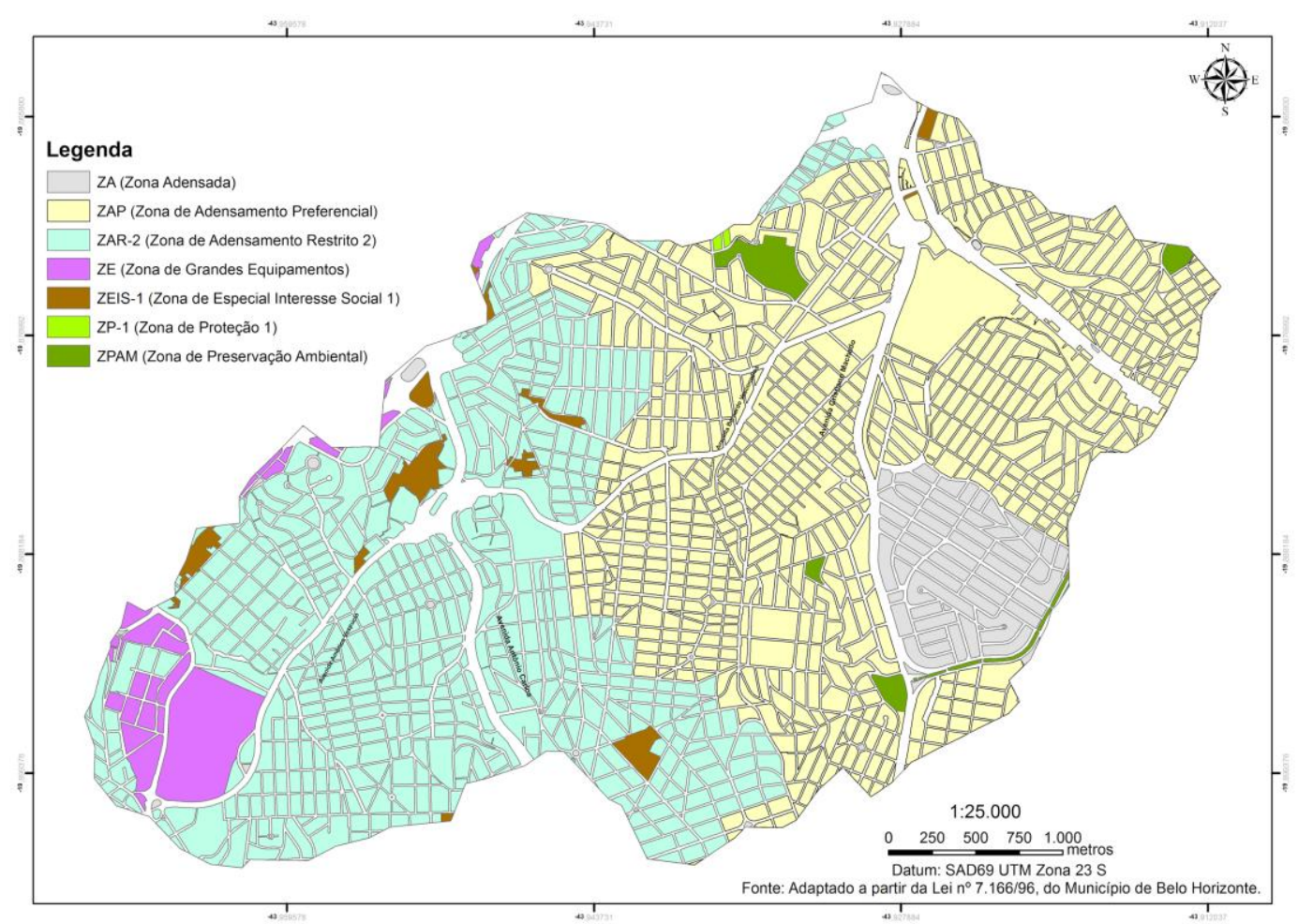

Figura 4. Zoneamento do uso e ocupação do solo de Belo Horizonte, aplicado a Sub-bacia do Ribeirão da Cachoeirinha. Fonte: Elaborado pelos autores, adaptado a partir da Lei nº 7166/96.

Diante da situação relativa às inundações a Prefeitura de Belo Horizonte decidiu implantar em 2011 uma rede de monitoramento e Alerta do Município, na qual são utilizados dados e informações coletadas por estações fluviométricas e pluviométricas. Para a sub-baciado cachoeirinha foram implantadas duas estações, sendo uma fluviométrica e outra Pluviométrica. O referido monitoramento estabelece uma classificação dos alertas quanto ao transbordamento das águas do curso d'água. Alerta amarelo: $50 \%$ da altura do canal fechado ou da restrição, no canal aberto; alerta laranja: $80 \%$ da altura do canal fechado ou da restrição, no canal aberto; alerta vermelho: extravasamento. No período 2011/2014 ${ }^{13}$ (BELO HORIZONTE. 2015, p.66). Segundo o sistema de monitoramento o Ribeirão da

\footnotetext{
${ }^{12}$ A referida área corresponde a ADE (Área de Diretriz Especial) da Bacia da Pampulha. As ADEs são áreas específicas que possuem aspectos próprios no que tange a regulação urbana, isto é, não estão submetidas ao zoneamento e suas condicionantes.

${ }^{13}$ O monitoramento para o ano de 2011 compreendeu os seguintes meses: Outubro, Novembro e Dezembro. Para o ano de 2012 os meses monitorados foram: Janeiro, Fevereiro, Março, Novembro e Dezembro. Em 2013 o monitoramento correspondeu aos meses de: Janeiro, Fevereiro, Março, Abril, Outubro, Novembro e Dezembro. Já em 2014 os seguintes meses foram monitorados: Janeiro, Fevereiro, Março e Abril.
} 
Cachoeirinha registrou 4 alertas vermelho, isto é, ocorreu o extravasamento das águas do Ribeirão para além dos leitos vazantes e menor. Segundo o Plano Municipal de Saneamento de Belo Horizonte (2015) os números de inundações justificam-se pelo desafio no estabelecimento de uma gestão integrada do sistema municipal de drenagem, em especial as "interferências com as redes de água e esgoto [...]”, o " [...] lançamento clandestinos de esgotos em redes de drenagem e de águas pluviais em redes coletoras de esgoto" contribuem para o aumento da vazão dos cursos d'água receptores de tais lançamentos (BELO HORIZONTE, 2015, p. 64). Ainda segundo o Plano Municipal de Saneamento de Belo Horizonte (2015), o número elevado de inundações e alagamentos também pode ser atribuído às obras de drenagem ainda não concluídas devido à escassez de recursos financeiros; a incapacidade do aparato técnico e administrativo em efetivar as demandas de obras de caráter emergencial e devido à ausência de um modelo de chuva x vazão calibrados

Outros mecanismos de gestão foram adotados pela Prefeitura de Belo Horizonte, como, por exemplo, o DRENURBS ${ }^{14}$ (Programa de Recuperação Ambiental e Saneamento dos Fundos de Vale e dos Córregos em Leito Natural de Belo Horizonte), NAC ${ }^{15}$ (Núcleo de Alerta de Chuvas), a produção de cartas de inundação sob responsabilidade da SUDECAP (Superintendência de Desenvolvimento da Capital) e SMURBE (Secretaria Municipal de Políticas Urbanas). Como alternativa a resolução da ocorrência de inundações para o Ribeirão da Cachoeirinha estão previstas a realização de obras para o Ribeirão da Cachoeirinha, tais obras prevêem a ampliação das seções dos canais e a adequação das declividades do Ribeirão da Cachoeirinha.

\section{CONSIDERAÇÕES FINAIS}

O processo de ocupação da sub-bacia do Ribeirão do Cachoeirinha e, consequentemente, as implicações ambientais que essa promoveu nos limites do local, apresentam as principais dinâmicas e desafios no que concerne a gestão do espaço urbano - em especial para os gestores públicos, como a prefeitura de Belo Horizonte, que abarcam a responsabilidade de regulação e/ou planejamento do espaço urbano. Diante das transformações promovidas - como infraestruturas viárias, adensamento populacional-residencial e comercial, equipamentos industriais, canalização e esgotamento de redes de drenagem -, o comportamento hidrológico da sub-bacia fora alterado de forma a acarretar em transformações, tanto na perspectiva ambiental como na social-material, que trouxeram impactos consideráveis na organização do espaço da sub-bacia. Partindo-se dessa perspectiva, a elaboração, por parte de gestores, de planos diretores que impliquem em estratégias fundamentadas no relacionamento

\footnotetext{
${ }^{14}$ O DRENURBS tem por finalidade:[...] promover a melhoria da qualidade de vida da população por meio da valorização do meio ambiente urbano atuando na despoluição dos cursos d'água, redução dos riscos de inundações, controle da produção de sedimentos e demais ações necessárias para o cumprimento de seu objetivo. (Art.2 ${ }^{\circ}$. DECRETO No 13.916 , DE 8 DE ABRIL DE 2010).

${ }^{15}$ Tal programa sob coordenadoria da SUDECAP (Superintendência de Desenvolvimento da Capital) consiste na capacitação e participação de voluntários que residem ou trabalham em áreas de risco de inundação.
} 
entre "[...] os componentes de manancial, esgotamento sanitário, resíduo sólido, drenagem urbana e inundação ribeirinha (TUCCI, 2004, p. 66)"; projetos de intervenção e obras de infraestrutura integralizados colocam-se essenciais, muito embora a utilização de tais instrumentos não possa se resumir a uma perspectiva teórico-proposital, onde sua elaboração se limite ao caráter emergencial e ao nível institucional-acadêmico de produção, sem realizar sua função produtiva e prática sobre o seu objeto e objetivos (VILLAÇA, 1998).

As inundações costumam estar atreladas também às obras de drenagem incapazes de drenar as águas de modo que não ocorra o extravasamento das águas até o leito maior. É evidente que a implementação e gestão incorreta de uma rede de drenagem de águas pluviais contribuem para um agravamento das inundações. Portanto, a opção por obras estruturais modificadoras do meio provavelmente não seja a alternativa mais adequada (TUCCI, p. 99-100).

O Zoneamento de Áreas Preferenciais de Adensamento- instrumento de gestão abordado nesse estudo -se mostra, a partir de uma análise de suas diretrizes e da ocupação ao longo da sub-bacia, concomitante a realidade de impactos existentes (MOL, 2004). Esse primeiro, a propósito, tem em sua construção a participação de setores e/ou atores sociais inseridos no espaço da cidade, cujos interesses de ocupação e exercício do espaço perpassam pelas intervenções, tanto propostas como ocorridas no ambiente da sub-bacia- assim como no município. Sendo assim, é notório pensar que as implicações ambientais no recorte de estudo não se resumem apenas a consequência da ocupação em sentido puro, isto é, consequente, mas sim de uma rede de interesses, articuladas pelo processo de adensamento urbano-econômico do espaço, bem como de um processo histórico de descentralização de adensamento e ocupação das regiões mais centrais da cidade (FELIPPE et al, 2011). Partindo dessa perspectiva, é importante refletir sobre as formas de gestão de espaços como o da Sub-bacia do Ribeirão da Cachoeira, onde a presença de dinâmicas ambientais - como a hídrica e geomorfológica são incididas pela intervenção antropogênica. Dessa forma, a revisão - ou, numa perspectiva mais ampla e sistêmica, a reformulação - de uma proposta de intervenção e regulação do espaço como o do Zoneamento de Áreas Preferenciais da prefeitura de Belo Horizonte seria uma tentativa de reverter um quadro histórico-espacial de degradação dos sistemas naturais presentes na Sub-bacia, bem como, a partir de uma reflexão de construção do espaço que não sobrepuje o desenvolvimento sócio espacial econômico sobre meio físico-natural, o controle e prevenção de inundações e impactos que também incidam sobre a ocupação urbana da área, corroborando assim com os objetivos norteadores que embasam planos diretores e zoneamentos: A gestão da cidade (VILLAÇA, 1998).

\section{REFERÊNCIAS BIBLIOGRÁFICAS}

BELO HORIZONTE. Decreto n ${ }^{\circ} 13.916$, de 8 de Abril de 2010.

Lei ${ }^{\circ} 7165$, de 27 de Agosto de 1996. 
Lei n ${ }^{\circ}$ 7166, de 27 de Agosto de 1996.

Lei ${ }^{\circ} 9.959$, de 20 de julho de 2010.

Plano Municipal de Saneamento de Belo Horizonte - 2012/2015, Atualização 2014.

Secretaria Municipal de Obras e Infraestrutura, 2015. 127p.

CAJAZEIRO, Joana Maria Drumond. Análise da susceptibilidade à formação de inundações nas bacias e áreas de contribuição do ribeirão Arrudas e córrego da Onça em termos de índices morfométricos e impermeabilização. Belo Horizonte: Dissertação (Mestrado), 2011. 92p.

CHAMPS, José Roberto Borges; et al. Planejamento do sistema de drenagem urbana na cidade de Belo Horizonte. In: Congresso Brasileiro de Engenharia Sanitária e Ambiental, XXI Feira Internacional de Tecnologias de Saneamento Ambiental, 4. ABES, 2001. p. 1-8.

EMBRAPA - Empresa Brasileira de Pesquisa Agropecuária. Serviço Nacional de Levantamento e Conservação de Solos (Rio de Janeiro, RJ). Súmula da 10. Reunião Técnica de Levantamento de Solos. Rio de Janeiro, 1979. 83p. (EMBRAPA-SNLCS. Miscelânea, 1).

FELIPPE, Miguel Fernandes; et al. Evolução da ocupação urbana das zonas preferenciais de recarga de aquíferos de Belo Horizonte-MG. Revista de Geografia-PPGEO-UFJF, v. 1, n. 2, 2016.

GOERL, R. F.; KOBIYAMA, M. Considerações a respeito das inundações no Brasil. Anais do XVI Simpósio Brasileiro de Recursos Hídricos, João Pessoa, v. 1, 2005, Cd-rom.

LEOPOLD, Luna B. Hydrology for urban land planning: A guidebook on the hydrologic effects of urban land use. USGS circ. 554. 1968. 18p.

MANUAL DE DESASTRES. Desastres Naturais - Vol. 1. Ministério da Integração Nacional, Secretaria Nacional de Defesa Civil. Brasília, 2003. 174p.

MIRANDA, E.E. de. Brasil em Relevo. Embrapa Monitoramento por Satélite. 2005. Disponível em: https://www.cnpm.embrapa.br/projetos/relevobr/

MOL, Natália Aguiar. Leis e Urbes - um estudo do impacto da Lei de Parcelamento, Ocupação e Uso do Solo de 1996 em Belo Horizonte. Belo Horizonte: Dissertação (Mestrado), 2004. 142p.

TOMINAGA, L. K.; SANTORO, J.; AMARAL, R. Desastres naturais: conhecer para prevenir. São Paulo: Instituto geológico. 196 p. ISBN 978-85-87235-09-1, 2009.

TUCCI, Carlos E. M. Águas Urbanas. Estudos avançados, v. 22, n. 63, p. 97-112, 2008.

Gerenciamento integrado das inundações urbanas no Brasil. Revista de Gestióndel Agua de América Latina, v. 1, n. 1, p. 59-73, 2004.

Plano diretor de drenagem urbana: princípios e concepção. Revista brasileira de recursos hídricos, v. 2, n. 2, p. 5-12, 1997.

; SILVEIRA, André. Gerenciamento da drenagem urbana. Revista Brasileira de Recursos Hídricos, v. 7, n. 1, p. 5-27, 2002.

VILLAÇA, Flávio. Dilemas do plano diretor. CEPAM. O município no século XXI: cenários e perspectivas. São Paulo: Fundação Prefeito Faria Lima-CEPAM, p. 237-247, 1999. 